\title{
Effect of Iron Lactate Overloading on Adenine Nucleotide Levels and Adenosine 3'-Monophosphate Forming Enzyme in Rat Liver and Spleen
}

\author{
Hiroyuki Fusimori, ${ }^{* a}$ Kiyokazu Ozaki, ${ }^{b}$ Tetsuro Matsuura, ${ }^{b}$ Shuuichi Matsushima, ${ }^{c}$ Isao Narama, ${ }^{b}$ \\ and Hidemitsu PAN-Hou ${ }^{a}$ \\ ${ }^{a}$ Department of Analytical Chemistry in Hygiene, Faculty of Pharmaceutical Sciences, Setsunan University; ${ }^{b}$ Department \\ of Pathology, Faculty of Pharmaceutical Sciences, Setsunan University; 45-1 Nagaotoge-cho, Hirakata, Osaka 573-0101, \\ Japan: and ${ }^{c}$ Pathology Section, Drug Safety Evaluation, Developmental Research Laboratories, Shionogi \& Co., Ltd.; \\ Toyonaka, Osaka 561-0825, Japan. Received April 12, 2004; accepted July 5, 2004
}

To elucidate the pathophysiological significance of adenosine $3^{\prime}$-monophosphate $\left(3^{\prime}\right.$-AMP) forming enzyme in rats, the effect of iron lactate overloading on the enzyme activities and adenine nucleotide levels in the liver and spleen was examined. Sprague-Dawley rats were fed a diet supplemented with $0 \%, 0.625 \%$ or $5.0 \%$ of iron lactate for 4 weeks. Iron deposition was found in periportal hepatocytes, Kupffer cells and macrophages of red pulp of the spleen. No significant changes in hematological parameters were detected. Although serum alkaline phosphatase and inorganic phosphorus levels elevated slightly in the 5.0\% group, activities of alanine aminotransferase and aspartate aminotransferase, and levels of serum urea nitrogen and creatinine were not changed significantly. The ATP levels in the liver and spleen of iron fed groups were significantly decreased, but adenosine 5'-diphosphate (ADP) and adenosine 5'-monophosphate (AMP) levels were within control levels. On the other hand, the levels of ATP, ADP and AMP in the erythrocytes without mitochondria were not suppressed by the iron lactate overloading. Free activity of $3^{\prime}$-AMP forming enzyme, one of ribonucleases (RNase), was not changed in the liver of iron-overloaded rat, and total amount of $3^{\prime}$-AMP and adenosine formed after the treatment of the crude enzyme(s) with p-chloromercuribenzensulfonic acid, a SH blocker of RNase inhibitors, was decreased dose-dependently. On the contrary, free activity of $3^{\prime}$-AMP forming enzyme was enhanced dose-dependently in the spleen of iron-overloaded rat but the total activity was not changed. However, the free and total $3^{\prime}$ AMP forming enzyme activities in the liver and spleen of iron-overloaded rats became equal at the dosage of $5.0 \%$ of iron lactate. The results obtained suggested that iron loading might induce significant decrease in hepatic and splenic ATP levels via malfunction of their mitochondria and might lead dissociation of RNase-RNase inhibitor complex to activate $3^{\prime}$-AMP forming enzyme in both tissues.

Key words adenosine 3'-monophosphate; iron overloading; rat; iron lactate; liver; spleen

Ribonuclease (RNase) is generally known to exist as complex with RNase inhibitor. ${ }^{1,2}$ The RNase inhibitor bound to the RNase is inactivated by modification of $\mathrm{SH}$ residues due to $\mathrm{SH}$ reagents such as $p$-chloromercuribenzensulfonic acid ( $p$ CMBS) and $p$-chloromercuribenzoic acid. ${ }^{1,2)}$ Regenerated RNase becomes active RNase, which is involved in the regulation of RNA metabolism and protein syntheses.

Intracellular adenosine 3 '-monophosphate (3'-AMP), one of the degradation products of RNAs, has been pharmacologically classified as an intracellular inhibitor of adenylate cyclase. ${ }^{3)}$ The 3'-AMP forming enzyme, one of RNases, exists not only in homogenates of several organs in rat $^{4}$ but also in mitochondria of rat liver. ${ }^{5,6)}$ However, the mode of existence of $3^{\prime}$-AMP forming enzyme in tissue and the pathophysiological roles of the enzyme have not yet been elucidated.

Excessive iron are stored as ferritin and hemosiderin in tissues. $^{7-10)}$ In normal rats, hemosiderin exists mainly in the macrophages of red pulp of the spleen. On the other hand, in iron-overloaded rats which fed diet supplemented with carbonyl iron or iron lactate for a few months, hemosiderin also deposited in hepatocytes and Kupffer cells in liver along with macrophages of red pulp of the spleen, suggesting that the liver is the main storage organ for excess iron. ${ }^{7,10)}$ Iron deposition has been thought to be responsible for cell damage ${ }^{7-12}$ ) via lipid peroxidation of cell membrane due to free radicals, ${ }^{11,13)}$ and intracellular changes in redox state of ferro and ferri, ${ }^{11,14)}$ therefore, iron overloading might affect the cellular ATP levels via malfunction of mitochondria and the activity of enzymes sensitive to modification of $\mathrm{SH}$ residues due to oxidative stress.

In this study, we examined the effect of 4-week-iron lactate loading on adenine nucleotide levels and the activity of 3'-AMP forming enzyme, which might exist as complex with $\mathrm{SH}$ residue-rich RNase inhibitor, in rat liver and spleen.

\section{MATERIALS AND METHODS}

Materials 3 '-AMP, adenosine 5'-monophosphate (AMP), adenosine $5^{\prime}$-diphosphate (ADP), ATP, adenosine (Ado), and poly (A) were purchased from Yamasa Shouyu (Chiba, Japan). Chloroacetaldehyde was from Wako Pure Chemicals Co. (Osaka, Japan). p-Chloromercuribenzensulfonic acid ( $p$ CMBS) was from Nacalai Tesque Inc. (Kyoto, Japan). An HPLC column $(150 \times 4.6 \mathrm{~mm}$ i.d.) of Chromatorex ODS (DU0005 MTP, $5 \mu \mathrm{m}$ ) and an anion-exchange resin of Hitachi gel No. 3013-N ( $5 \mu \mathrm{m})$ were kindly supplied by Fuji Silysia Chemical, Ltd. (Aichi, Japan) and by Hitachi (Tokyo, Japan), respectively. Other chemicals of reagent grade were obtained commercially. Male 4-week-old Sprague-Dawley rats were purchased from Charles River Japan Inc. (Hino, Japan). A powdered commercial diet (CRF-1) and iron lactate were obtained from Oriental Yeast (Tokyo, Japan) and Musashino Chemical Inc. (Tokyo, Japan), respectively.

Animals and Diets After acclimazation for $7 \mathrm{~d}$, the rats were divided into 3 groups of 10 each, receiving $0,0.625$ and $5.0 \%$ of iron lactate in a powdered commercial diet and were 
supplied with tap water ad libitum throughout the exposure period for 4 weeks. Rats were individually housed in polycarbonate cages in an animal room air-conditioned at a temperature of $23 \pm 2{ }^{\circ} \mathrm{C}$ and a relative humidity of $55 \pm 10 \%$ with 15 times ventilation per hour under a 12-h light and dark cycle. The dosage level of $5.0 \%$ is corresponding to 3000 times of nutritional requirement level for human.

Hematology and Serum Biochemistry At the end of the 4-week feeding period, the blood was withdrawn from the abdominal aorta of the rat under light ether anesthesia. Routine hematological parameters, i.e. white blood cell count (WBC), red blood cell count (RBC), hemoglobin concentration (HGB), packed cell volume (PCV) and platelet count (PLT), were examined by an automated blood analyzer (Sysmex E-400, Toa, Japan). Routine serum biochemical parameters, i.e. aspartate aminotransferase (AST), alanine aminotransferase (ALT), alkaline phosphatase (ALP), creatine kinase (CK), creatinine (CRE), blood urea nitrogen (BUN), inorganic phosphorus (IP) and iron, were also examined with an automated analyser (Hitachi 170, Japan or Au 510, Olympus, Japan).

Histopathology All rats were sacrificed under deep ether anesthesia at the end of the administration period and necropsied. The liver and spleen were weighed and then fixed in $10 \%$ phosphate-buffered formalin ( $\mathrm{pH} 7.4)$. Tissue samples were dehydrated in a graded series of ethanol, embedded in paraffin, and $4-\mu \mathrm{m}$-thick sections were stained with hematoxylin and eosin. Representative sections were also stained with Berlin blue for $\mathrm{Fe}^{3+}$ and Turnbull blue for $\mathrm{Fe}^{2+}$.

Preparation of Tissue Homogenate The liver and spleen were quickly removed from rat, and weighed. The tissue fragments $(1 \mathrm{~g})$ from the liver and spleen were homogenized immediately after removal in $19 \mathrm{ml}$ of $20 \mathrm{~mm}$ Tris- $\mathrm{HCl}$ buffer ( $\mathrm{pH} 7.5$ ) containing $0.25 \mathrm{M}$ sucrose, $1 \mathrm{~mm}$ EDTA and $5 \mathrm{~mm} 2$-mercaptoethanol. The homogenates were then centrifuged at $14000 \times \boldsymbol{g}$ for $20 \mathrm{~min}$. The supernatants obtained were kept at $-40{ }^{\circ} \mathrm{C}$ until use, and used as a crude enzyme solution.

Determination of Adenine Compounds by HPLC Extraction of adenine compounds in the liver, spleen and blood with perchloric acid was carried out according to the method described by us. ${ }^{5)}$ The acid-soluble compounds were treated with $40 \%$ chloroacetaldehyde for fluorescence detection. ${ }^{15}$ ) The derivatized compounds were analyzed with an HPLC system consisting of an Intelligent HPLC pump (Jasco 880FP, Japan), an Intelligent spectrofluorometer (Jasco 820-FP, Japan) and an integrator (Jasco 829-IT, Japan) using a column of a Hitachi gel No. 3013-N as an anion exchanger. ${ }^{15)}$

Determination of Free and Total $3^{\prime}$-AMP Forming Enzyme Activity Free 3'-AMP forming enzyme activity was determined according to the procedure described previ-

Table 2. Serum Biochemical Findings in Iron Lactate-Overloaded Rats

\begin{tabular}{|c|c|c|c|c|c|c|c|c|}
\hline $\begin{array}{c}\text { Iron lactate } \\
(\%)\end{array}$ & $\begin{array}{l}\text { AST } \\
(\mathrm{IU} / 1)\end{array}$ & $\begin{array}{l}\text { ALT } \\
(\mathrm{IU} / 1)\end{array}$ & $\begin{array}{l}\text { ALP } \\
(\mathrm{IU} / 1)\end{array}$ & $\begin{array}{c}\mathrm{CK} \\
(\mathrm{IU} / \mathrm{l})\end{array}$ & $\begin{array}{c}\text { BUN } \\
(\mathrm{mg} / \mathrm{dl})\end{array}$ & $\begin{array}{c}\text { CRE } \\
(\mathrm{mg} / \mathrm{dl})\end{array}$ & $\begin{array}{c}\text { IP } \\
(\mathrm{mg} / \mathrm{dl})\end{array}$ & $\begin{array}{l}\text { Iron } \\
(\mu \mathrm{g} / \mathrm{dl})\end{array}$ \\
\hline 0 & $95.0 \pm 0.86$ & $21.20 \pm 0.21$ & $326.1 \pm 9.7$ & $405.7 \pm 13.3$ & $13.32 \pm 0.39$ & $0.255 \pm 0.003$ & $7.80 \pm 0.06$ & $184.4 \pm 4.9$ \\
\hline 0.625 & $104.0 \pm 2.11$ & $19.30 \pm 0.26$ & $285.7 \pm 3.7$ & $509.6 \pm 17.0 *$ & $12.25 \pm 0.17$ & $0.247 \pm 0.003$ & $8.52 \pm 0.06^{*}$ & $179.3 \pm 6.3$ \\
\hline 5 & $104.0 \pm 2.01$ & $23.4 \pm 0.66$ & $357.3 \pm 8.4^{*}$ & $460.1 \pm 15.4^{*}$ & $13.88 \pm 0.29$ & $0.255 \pm 0.003$ & $10.44 \pm 0.06^{*}$ & $198.0 \pm 7.3$ \\
\hline
\end{tabular}

Data are expressed as mean \pm S.E.M. $* p<0.05 v$ s. control group. etate buffer ( $\mathrm{pH} 5.8$ ) containing $20 \mathrm{~mm}$ EDTA, $25 \mu \mathrm{g}$ poly (A) and $5 \mu \mathrm{l}$ of various crude enzyme solution. After incubation of the mixture at $37^{\circ} \mathrm{C}$ for $60 \mathrm{~min}$, the reaction was stopped by the addition of $55 \mu \mathrm{l}$ of $15 \mathrm{mM} \mathrm{ZnCl}_{2}$ in $0.5 \mathrm{M}$ perchloric acid. In order to determine total 3 '-AMP forming enzyme activity, $4 \mu \mathrm{l}$ of $5.5 \mathrm{~mm} p \mathrm{CMBS}$ were added to the reaction mixture for the free enzyme activity. The enzymic products were derivatized with chloroacetaldehyde and the derivatized compounds were analyzed using a column of Chromatorex ODS maintained at $45^{\circ} \mathrm{C}$. ${ }^{16)}$

Statistical Analysis All data are expressed as mean士 S.E.M. Statistical evaluation of the data was performed using Student's $t$-test. $p$ values $<0.05$ were considered to be significant.

\section{RESULTS}

The body weights of the $5.0 \%$ group were significantly suppressed to $c a .79 \%$ of those of control group as shown in Table 1 . The relative liver weight was significantly higher in $5.0 \%$ iron lactate loading group, and the relative spleen weight was lower in $0.625 \%$ iron lactate loading group comparing with those in control group (Table 1).

Iron lactate overloading had no effect on WBC, RBC, HGB, PCV and PLT of hematological parameters (data not shown). The activities of serum ALP and CK, and IP levels were significantly elevated in the $5.0 \%$ group. No significant increase in the serum iron levels as well as the activities of AST and ALT, and in the levels of BUN and CRE were observed as shown in Table 2.

In the liver, brown pigment depositions were observed only in the periportal hepatocytes and Kupffer cells of the $5.0 \%$ group. Brown pigments were severely stained as blue granules by Berlin blue, and were identified as $\mathrm{Fe}^{3+}$ (Fig. 1B). $\mathrm{Fe}^{3+}$-positive blue granules slightly deposited in the midzonal and perilobular hepatocytes of the $5.0 \%$ group (Fig. 1B). No blue-stained iron granules were observed in the control (Fig. 1A) and $0.625 \%$ group (data not shown). Severe iron $\left(\mathrm{Fe}^{2+}\right)$ deposits were also detected in periportal hepato-

Table 1. Effect of Iron Lactate on Body Weight and Relative Organ Weight

\begin{tabular}{lclc}
\hline \hline \multirow{2}{*}{$\begin{array}{c}\text { Iron lactate } \\
(\%)\end{array}$} & $\begin{array}{c}\text { Body weight } \\
(\mathrm{g})\end{array}$ & \multicolumn{2}{c}{ Relative organ weight $(\%)^{a)}$} \\
\cline { 3 - 4 } & & Liver & Spleen \\
\hline 0 & $209.1 \pm 8.2$ & $2.87 \pm 0.07$ & $0.212 \pm 0.010$ \\
0.625 & $208.1 \pm 6.2$ & $2.82 \pm 0.04$ & $0.184 \pm 0.007^{*}$ \\
5 & $165.4 \pm 2.8^{*}$ & $3.10 \pm 0.04^{*}$ & $0.200 \pm 0.007$ \\
\hline
\end{tabular}

Data are expressed as mean \pm S.E.M. a) $100 \times$ organ weight $(\mathrm{g}) /$ body weight $(\mathrm{g})$ $* p<0.05 v s$. control group. 

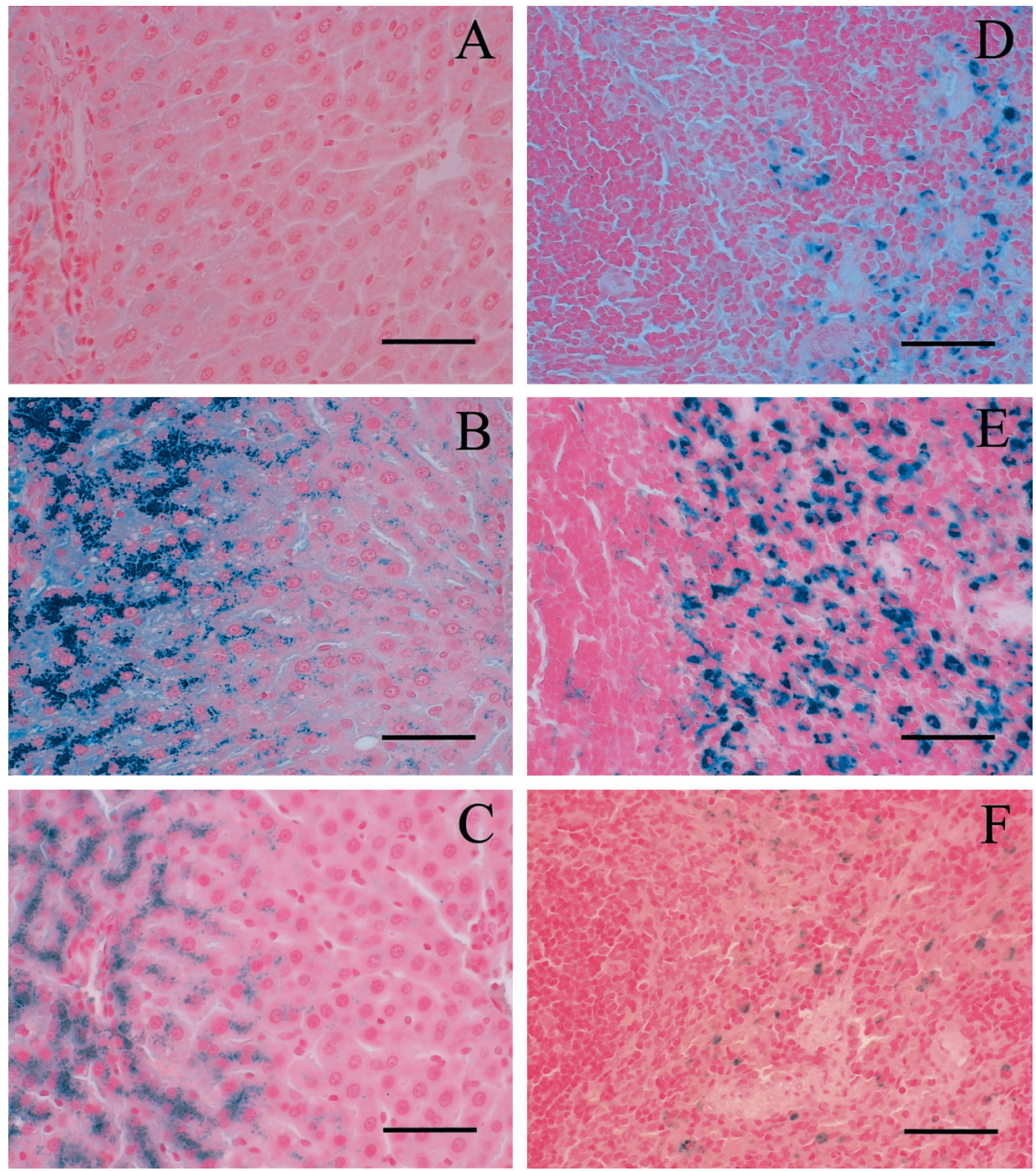

Fig. 1. Photomicrographs of Liver and Spleen from Rat Fed Iron Lactate

A: liver of control group. No deposition of iron is detected., B: liver of 5.0\% group. Severe iron deposition (blue stained granules) are found in the periportal hepatocytes., C: liver of 5.0\% group. Severe iron deposition (dark blue stained granules) are detected in periportal hepatocytes., D: spleen of control group. Slight iron deposition (blue stained granules) are detected in the reticuloendothelial cells in red pulp., E: spleen of $5.0 \%$ group. Severe iron deposition are found in the reticuloendothelial cells in red pulp., F: spleen of 5.0\% group. Very slight iron deposition (dark brown stained granules) are found in the cells in red pulp. Berlin blue stain (A, B, D and E), Turnbull blue stain (C and F). Scale bars in panels are $50 \mu \mathrm{m}$.

Table 3. Adenine Nucleotide Levels in Liver and Spleen of Iron Lactate-Overloaded Rats

\begin{tabular}{ccccc}
\hline \hline \multirow{2}{*}{ Tissue } & & & $\mathrm{nmol} / \mathrm{mg}$ wet weight \\
\cline { 3 - 4 } & Iron lactate (\%) & ATP & ADP & AMP \\
\hline \multirow{2}{*}{ Liver } & 0 & $1.89 \pm 0.15$ & $1.16 \pm 0.10$ & $2.33 \pm 0.19$ \\
& 0.625 & $1.32 \pm 0.05^{*}$ & $0.85 \pm 0.04^{*}$ & $2.52 \pm 0.08$ \\
Spleen & 5 & $0.94 \pm 0.13^{*}$ & $0.94 \pm 0.10$ & $1.32 \pm 0.04$ \\
& 0 & $1.59 \pm 0.07$ & $1.19 \pm 0.06$ & $1.02 \pm 0.05$ \\
& 0.625 & $1.32 \pm 0.12$ & $1.24 \pm 0.06$ & $0.97 \pm 0.09$ \\
\end{tabular}

Data are expressed as mean \pm S.E.M. $* p<0.01 v s$. control.

cytes (Fig. 1C). In addition, no hepatocytes damage in rats of all groups was confirmed by the morphological studies. In the spleen, iron deposits were observed in the reticuloendothelial cells in red pulp of all of the groups (Fig. 1D). The amount of iron $\left(\mathrm{Fe}^{3+}\right)$ deposits increased dose-dependently (Fig. 1E). Very slight iron $\left(\mathrm{Fe}^{2+}\right)$ deposits were found in the reticuloendothelial cells (Fig. 1F).

Hepatic ATP levels in iron-overloaded rats significantly decreased dose-dependently, and the ATP levels in the 5.0\% group was $c a .50 \%$ of the control levels (Table 3 ). Iron lactate overloading had no effect on individual levels of ADP and AMP in the $5.0 \%$ group. As shown in Table 3, splenic 
Table 4. Adenine Nucleotide Levels in Erythrocytes of Iron Lactate-Overloaded Rats

\begin{tabular}{cccc}
\hline \hline \multirow{2}{*}{$\begin{array}{c}\text { Iron lactate } \\
(\%)\end{array}$} & \multicolumn{3}{c}{$\mathrm{pmol} / 10^{2}$ erythrocytes } \\
\cline { 2 - 4 } & ATP & ADP & AMP \\
\hline 0 & $85.7 \pm 4.4$ & $16.3 \pm 0.5$ & $1.8 \pm 0.1$ \\
0.625 & $99.6 \pm 4.1^{*}$ & $18.3 \pm 0.4^{*}$ & $1.8 \pm 0.1$ \\
5 & $93.0 \pm 4.5$ & $15.5 \pm 0.5$ & $1.5 \pm 0.1^{*}$ \\
\end{tabular}

Data are expressed as mean \pm S.E.M. $* p<0.05$ vs. control.
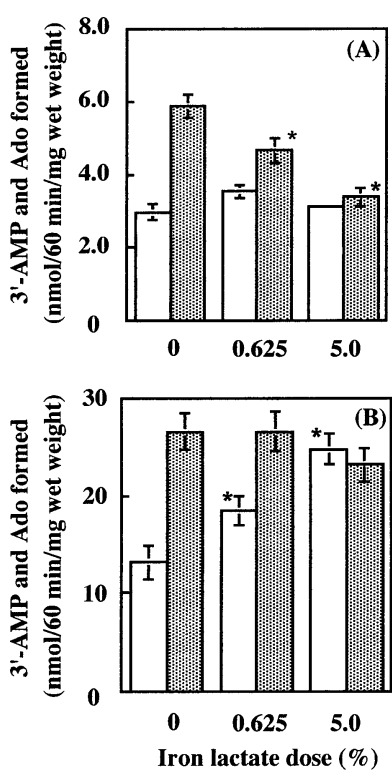

Fig. 2. Effect of Iron Lactate Overloading on Free and Total Activities of 3'-AMP Forming Enzyme(s) in Rat Liver (A) and Spleen (B)

$\square$ : free activity of 3 '-AMP forming enzyme, $\square$ : total activity of 3 'AMP forming enzyme, $* p<0.05 v s$. control.

ATP levels in the $5.0 \%$ group also significantly decreased to ca. $66 \%$ of those in control group. No significant changes in ADP and AMP levels were observed (Table 3). On the other hand, the levels of ATP and ADP in the erythrocytes of the $0.625 \%$ group slightly but significantly increased to $c a$. 1.16 and 1.12-fold, respectively (Table 4). No significant changes in the ATP levels in the cells of the $5.0 \%$ group were observed, but the AMP levels in the cells of the 5.0\% group significantly decreased to $c a .83 \%$ of those in control group.

In the iron-overloaded rat liver, the free activity of 3 '-AMP forming enzyme was not changed, and total activity of the enzyme in the crude enzyme solution treated with $p$ CMBS was decreased dose-dependently (Fig. 2A). At the dosage of $5.0 \%$ iron lactate, the total $3^{\prime}$-AMP forming enzyme activity was equal to the free activity. In the spleen of iron-overloaded rats, the free activity of $3^{\prime}$-AMP forming enzyme was significantly increased in a dose-dependent manner (Fig. 2B). Total activity of the enzyme in splenic crude enzyme solution treated with $p$ CMBS was not changed by the iron overloading. Free enzyme activities were equal to the total activities in the spleen of the $5.0 \%$ group.

\section{DISCUSSION}

Chronic iron overload has been reported to induce various pathological changes such as liver injury, ${ }^{8,17,18)}$ liver fibrosis, ${ }^{8,18)}$ nephropathy, ${ }^{19)}$ myocardial degeneration, ${ }^{20)}$ eosinophilic gastroenterocolitis, ${ }^{21)}$ and osteomalacia ${ }^{22)}$ in rats fed diets containing several percents of carbonyl iron or iron lactate for over a few months. Under our experimental conditions employed, the activities of AST and ALT as biomarkers for hepatic function, and the levels of BUN and CRE as biomarkers for renal function and the levels of blood iron levels were not changed (Table 2), suggesting that neither hepatic damage $^{23)}$ and renal dysfunction ${ }^{17)}$ nor impairment of mechanism to keep serum iron levels were induced by the 4-week iron lactate overloading. Large amount of iron deposits were histochemically found in hepatocytes and reticuloendothelial cells in the liver and spleen (Fig. 1) as reported by Matsuno et $a l .{ }^{7)}$ As iron lactate exposure periods were relatively shortterm, no significant cell damages were detected from histopathological and serum biochemical studies (Table 2).

Cellular ATP levels are generally regulated by metabolic balances between ATP-generating processes due to glycolytic and oxidative metabolism and ATP-consuming processes. Hepatocytes, splenic reticuloendothelial cells and macrophages contain mitochondria to generate almost all the cellular ATP under aerobic conditions. Iron lactate overload resulted in a marked and dose-dependent decrease in hepatic ATP levels with no change in ADP and AMP levels (Table 3) although iron deposits in periportal hepatocytes (Figs. 1B, C) did not enhance the activities of serum AST and ALT suggesting the impaired liver function (Table 2). These results showing changes in adenine nucleotide levels are in agreement with the data reported by Bacon et al. ${ }^{24)}$ In addition, splenic ATP levels but not ADP and AMP levels were found to be reduced by the loading (Table 3). As shown in Table 4, no significant reduction of ATP levels in the erythrocytes which generate cellular ATP via glycolysis of glucose was evident in the present rats, suggesting that cellular iron had no effect on ATP generation via glycolysis. Bacon et al. ${ }^{24)}$ have reported that chronic iron overload decreases hepatic mitochondrial cytochrome $\mathrm{c}$ oxidase activity and hepatic ATP levels. Together with Bacon's observation, these results obtained above suggested that the hepatic and splenic ATP depletion might be associated with the alteration in mitochondrial oxidative mechanism by intracellular iron levels.

Rat liver cytosol and microsome are known to possess several kinds of RNases, which have already purified. ${ }^{25-29)}$ Rat liver cytosolic RNases did not hydrolyze poly (A) as substrate $^{25,26)}$ and produced oligoadenylate ${ }^{27)}$ but microsomal exoribunuclease $^{28)}$ and endoribonuclease ${ }^{29)}$ released 5'-AMP and oligoadenylate, respectively, from poly (A) in the range of alkaline $\mathrm{pH}$. As hepatic and splenic $3^{\prime}$-AMP forming enzyme(s) released mainly $3^{\prime}$-AMP but not $5^{\prime}$-AMP from poly (A) in acidic condition of $\mathrm{pH} 5.8$ (Fig. 2), these enzyme(s) seemed to be different from alkaline RNases reported by others. ${ }^{25-29)}$

In general, RNase exists as both an active form and an inactive form complexed with RNase inhibitor in tissue. ${ }^{1)}$ The inactivation of RNase inhibitor by $\mathrm{SH}$ reagents causes the dissociation of the RNase-RNase inhibitor complex into active RNase and inactive inhibitor, ${ }^{2)}$ in which $\mathrm{SH}$ residues are important for the inhibition of RNase. RNases do not catalyze release of Ado directly from RNAs. Conversion of 3'AMP to Ado is catalyzed by acid phosphatase, ${ }^{16)}$ and then 
the yielded Ado is converted to inosine, which is not determined by our HPLC using chloroacetaldehyde, by Ado deaminase. Therefore, the net 3'-AMP forming enzyme activity is estimated by the sum of the activity to produce $3^{\prime}$ AMP and Ado. In control group, free activity of 3'-AMP forming enzyme was $c a$. 50\% of total enzymic activity (Figs. $2 \mathrm{~A}, \mathrm{~B}$ ), suggesting that the $3^{\prime}$-AMP forming enzymes in crude enzyme solution from the liver and spleen composed of the nearly equal activity of active RNase and inactive RNase which bound to RNase inhibitor. In the $5.0 \%$ group, total activities of $3^{\prime}$-AMP forming enzyme(s) in the crude enzyme solution treated with $p$ CMBS became equal to free activities of the enzyme(s) (Figs. 2A, B), indicating that almost all the $3^{\prime}$-AMP forming enzymes in the liver and spleen existed as active RNase. Korge and Campbell ${ }^{14)}$ have demonstrated that creatine kinase, $\mathrm{Ca}^{2+}$-ATPase and pyruvate kinase, representative SH enzymes in muscle, were activated or inactivated by depending on the redox state of ferro and ferri. Dose-dependent increase in free activity of $3^{\prime}$-AMP forming enzyme in spleen by iron lactate loading (Fig. 2B) suggested that $\mathrm{Fe}^{3+}$ deposits in reticuloendothelial cells might involve in inactivation of the RNase inhibitor. This result also reveals that large amount of the forming enzyme(s) might localize in the cells in red pulp of the spleen. After the iron loading, large amounts of $\mathrm{Fe}^{3+}$ and $\mathrm{Fe}^{2+}$, which were stained as Berlin blue granules and Turnbull blue granules, respectively, were histochemically found in periportal hepatocytes (Figs. 1B, C). The distribution balance between $\mathrm{Fe}^{3+}$ and $\mathrm{Fe}^{2+}$ deposited in the hepatocytes might be regulated by the redox state of reducing and oxidizing biomolecules in liver. The $\mathrm{Fe}^{2+}$ found in the hepatocytes might derive from the reduction of $\mathrm{Fe}^{3+}$ by glutathione which has been reported to be existed in liver several $\mu \mathrm{mol} / \mathrm{g}$ wet weight level. ${ }^{12,19)}$ Reduction of $\mathrm{Fe}^{3+}$ to $\mathrm{Fe}^{2+}$ might result in suppressing the $\mathrm{Fe}^{3+}$-evoked $3^{\prime}$-AMP forming activity via inactivation of RNase inhibitor by $\mathrm{Fe}^{3+}$ as seen in iron-loaded spleen (Fig. 2B). The resultant $\mathrm{Fe}^{2+}$ deposited in hepatocytes might activate the acid phosphatase $(\mathrm{s})^{13)}$ and Ado deaminase ${ }^{30)}$ metabolizing enzymes of $3^{\prime}$-AMP and Ado. These speculations are consistent with our results that the total activity of the forming enzyme was decreased in the liver and the free activity of the enzyme was enhanced in the spleen in a dose-dependent fashion obtained in Fig. 2. The levels of $\mathrm{Fe}^{3+}$ and $\mathrm{Fe}^{2+}$ in the liver and spleen should be determined to elucidate detailed mechanism for fluctuation of 3 '-AMP forming enzyme after iron loading.

Decrease in cellular ATP levels may reflect mitochondrial dysfunction and alter calcium homeostasis. ${ }^{11)}$ As EDTAchelatable divalent cations such as $\mathrm{Ca}^{2+}$ had inhibitory effects on $3^{\prime}$-AMP forming enzyme activity, ${ }^{16)}$ leakage of $\mathrm{Ca}^{2+}$ from mitochondria may activate mitochondrial $3^{\prime}$-AMP forming enzyme. Although the localization, biochemical properties and activation mechanism of 3 '-AMP forming enzyme(s) in tissues are still unknown, the changes in $3^{\prime}$-AMP forming enzyme activity in cytosol and mitochondria in rat may affect hepatic and splenic functions via modulation of adenylate cyclase and AMP-dependent enzymic reactions associated with degradation of various RNAs, especially poly
(A). Further studies are needed to understand the physiological and pathophysiological roles of 3'-AMP forming enzyme(s).

Acknowledgments The authors wish to thank Mr. M. Yugawa of Musashino Chemical Laboratory Co. Ltd., for providing the iron lactate test material and Dr. T. Hirooka of this University for his technical assistance.

\section{REFERENCES}

1) Kumagai H., Matsuura M., Murakami A., Hirose S., Chem. Pharm. Bull., 39, 137-141 (1991).

2) Ferreras M., Gavilanes J. G., Lopez-Otin C., Garcia-Segura J. M., J. Biol. Chem., 270, 28570-28578 (1995).

3) Johnson R. A., Yeung S. H., Stubner D., Bushfield M., Shoshani I., Mol. Pharmacol., 35, 681-688 (1989).

4) Bushfield M., Shoshani I., Johnson R. A., Mol. Pharmacol., 38, 848 853 (1990).

5) Fujimori H., Pan-Hou H., Biol. Pharm. Bull., 21, 624-627 (1998).

6) Fujimori H., Pan-Hou H., J. Health Sci., 48, $204-207$ (2002).

7) Matsuno T., Nori M., Awai M., Acta Med. Okayama, 39, 347-360 (1985).

8) Park C. H., Bacon B. R., Brittenham G. M., Tavill A. S., Lab. Invest., 57, 555-563 (1987)

9) Halliday J. W., Searle J., BioMetals, 9, 205-209 (1996).

10) Papanastasiou D. A., Vayenas D. V., Vassilopoulos A., Repanti M., Pathol. Res. Pract., 196, 47-54 (2000).

11) Britton R. S., Seminars Liver Dis., 16, 3-12 (1996).

12) Stal P., Johansson I., Ingelman-Sundberg M., Hagen K., Hultcrantz R., J. Hepatol., 25, 538-546 (1996).

13) Bacon B. R., Britton R. S., Hepatology, 11, 127-137 (1990).

14) Korge P., Campbell K. B., Arch. Biochem. Biophys., 304, 420-428 (1993).

15) Fujimori H., Yamauchi M., Pan-Hou H., Chem. Express, 6, 715-718 (1991).

16) Fujimori H., Sato R., Yasuda M., Pan-Hou H., Biol. Pharm. Bull., 21, 1348-1351 (1998).

17) Narama I., Ozaki K., Matsuura T., Maruyama H., J. Toxicol. Pathol., 12, 105-111 (1999).

18) Figueiredo M. S., Baffa O., Barbieri N. J., Zago M. A., Res. Exp. Med. (Berlin), 193, 27-37 (1993).

19) Pietrangelo A., Borella F., Casalgrandi G., Montosi G., Ceccarelli D., Gallesi D., Giovannini F., Gasparetto A., Masini A., Gastroenterology, 109, 1941-1949 (1995).

20) Whittaker P., Hines F. A., Robl M. G., Dunkel V. C., Toxicol. Pathol., 24, 558-563 (1996).

21) Narama I., Ozaki K., Matsushima S., Matsuura T., Toxicol. Pathol., 27, $318-324$ (1999).

22) Matsushima S., Torii M., Ozaki K., Narama I., Toxicol. Pathol., 31, 646-654 (2003).

23) Poli G., Albano E., Dianzani M. U., Chem. Phys. Lipids, 45, 117-142 (1987).

24) Bacon B. R., O’Neill R., Britton R. S., Gastroenterology, 105, 1134 1140 (1993).

25) Kumagai H., Kato H., Igarashi K., Hirose S., J. Biochem. (Tokyo), 94, $71-77$ (1983).

26) Brockdorff N. A., Knowler J. T., Eur. J. Biochem., 163, 89—95 (1987).

27) Sawai Y., Yanokura M., Tsukada K., J. Biochem. (Tokyo), 86, 757764 (1979).

28) Kumagai H., Igarashi K., Tanaka K., Nakao H., Hirose S., Biochim. Biophys. Acta, 566, 192-199 (1979).

29) Kumagai H., Igarashi K., Takayama T., Watanabe K., Sugimoto K., Hirose S., Biochim. Biophys. Acta, 608, 324-331 (1980).

30) Kobayashi F., Ikeda T., Marumo F., Sato C., Am. J. Gastroenterol., 88, 266-271 (1993). 